\title{
Ankle mechanics during sidestep cutting implicates need for 2-degrees of freedom powered ankle-foot prostheses
}

\author{
Evandro M. Ficanha; ${ }^{1}$ Mohammad Rastgaar, PhD; ${ }^{*}$ Kenton R. Kaufman, $\mathbf{P h D}^{\mathbf{2}}$ \\ ${ }^{1}$ Department of Mechanical Engineering-Engineering Mechanics, Michigan Technological University, Houghton, MI; \\ ${ }^{2}$ Motion Analysis Laboratory, Department of Orthopedic Surgery, Mayo Clinic, Rochester, MN
}

\begin{abstract}
The ankle joint of currently available powered prostheses is capable of controlling one degree of freedom (DOF), focusing on improved mobility in the sagittal plane. To increase agility, the requirements of turning in prosthesis design need to be considered. Ankle kinematics and kinetics were studied during sidestep cutting and straight walking. There were no significant differences between the ankle sagittal plane mechanics when comparing sidestep cutting and straight walking; however, significant differences were observed in ankle frontal plane mechanics. During straight walking, the inversion-eversion (IE) angles were smaller than with sidestep cutting. The ankle that initiated the sidestep cutting showed progressively increasing inversion from 2 to 13 degrees while the following contralateral step showed progressively decreasing inversion from 8 to -4 degrees during normal walking speed. The changes in IE kinematics were the most significant during sidestep cutting compared with straight walking. The IE moments of the step that initiated the sidestep cutting were always in eversion, acting as a braking moment opposing the inverting motion. This suggests that an ankle-foot prosthesis with active DOFs in the sagittal and frontal planes will increase the agility of gait for patients with limb loss.
\end{abstract}

Key words: ankle kinematics, ankle kinetics, ankle moments, degrees of freedom, gait analysis, human ankle impedance, human ankle mechanics, prosthetic, sidestep cutting, turning maneuvers.

\section{INTRODUCTION}

Recent advances in powered prostheses promise to significantly improve the quality of life and well-being for individuals with impaired mobility. A better understanding of the complexities surrounding lower-limb prostheses, which are needed for walking and daily activities, will lead to increased health and well-being for the 1.7 million people with amputation in the United States, the majority of whom have lower-limb amputations [12]. The ankle joint of current commercially available lower-limb powered prostheses is capable of controlling only one degree of freedom (DOF) in the sagittal plane, focusing on improved mobility in straight walking. Turning, however, plays a major role in daily living activities and requires ankle control in both the sagittal and frontal planes. Additionally, even during walking on a straight path, the ankle functions in both the sagittal and frontal planes. This suggests that the next advancement in prosthetic ankles is to extend their design and control to the frontal plane.

Abbreviations: $\mathrm{DOF}=$ degree of freedom, $\mathrm{DP}=$ dorsiflexionplantar flexion, EI = external-internal rotation, IE = inversioneversion, ISB = International Society of Biomechanics, MS = mid-stance, $\mathrm{TP}=$ terminal stance and pre-swing, $\mathrm{WA}=$ weight acceptance.

*Address all correspondence to Mohammad Rastgaar, PhD; Department of Mechanical Engineering-Engineering Mechanics, Michigan Technological University, 820 R. L. Smith MEEM Building, 1400 Townsend Dr, Houghton, MI 49931; 906-487-1416; fax: 906-487-2822.

Email: Rastgaar@mtu.edu

http://dx.doi.org/10.1682/JRRD.2014.02.0043 
Agility describes the ability to alter the direction of the body efficiently and effectively. One definition of agility is proposed as "a rapid whole body movement with change of velocity or direction in response to a stimulus” [3]. Agility requires both maneuverability and speed, which are limited in people with lower-limb amputation who use passive prostheses. It is shown that individuals with unilateral below-knee amputation who use passive prostheses rely more on their hip joint and expend 20 to 30 percent more metabolic energy than nondisabled people at the same speed. As a result, their preferred speed of gait is 30 to 40 percent lower than that of nondisabled people [4-5]. Additionally, people with amputation use compensatory strategies that result in asymmetrical gait patterns that affect joints in both lower limbs, which may inadvertently lead to secondary complications such as back pain or knee or hip osteoarthritis of the intact limb [6-9]. In contrast, it has been shown that a powered ankle-foot prosthesis reduces the metabolic costs of people with unilateral transtibial amputation during straight walking by providing sufficient power during push-off [10-11]. However, studies of four representative daily activities show that turning steps may account for an average of 25 percent of steps, ranging from 8 to 50 percent of all steps depending on the activity [12], which people with amputation accomplish using different control strategies than nondisabled people. While a nondisabled person relies on hip movement in the coronal plane and moments generated at the ankle, a person with amputation using a passive prosthesis relies on hip extension in the sagittal plane [13-16]. During a turn, modulation of ankle impedance in the sagittal and frontal planes plays a major role in controlling lateral and propulsive ground reaction forces in order to accelerate the body's center of mass along the gait path; thus, during a turning step, lateral and propulsive impulses are larger than during a straight step [17]. This difference will result in different gait strategies between people with amputation and nondisabled people to compensate for the lack of propulsion from a passive prosthesis in order to increase maneuverability [13]. This suggests that an ankle-foot prosthesis capable of generating moments in two DOFs, i.e., dorsiflexion-plantar flexion (DP) and inversion-eversion (IE) directions, with impedance modulation similar to the human ankle will augment maneuverability and mobility that leads to a more agile gait. Additionally, design features that allow walking in arbitrary directions on slopes while conforming the foot to the uneven ground profile may result in a more efficient gait.

Understanding the ankle's capability to modulate impedance while generating net positive work during the stance period of gait has influenced the design of new ankle-foot prostheses [18-21]. The ankle mechanical impedance is a dynamic operator that maps the timehistory of angular displacements onto the corresponding time-history of ankle moments. While these prostheses have advanced the state-of-the-art design, they are specifically designed for different gait scenarios in the sagittal plane. The design strategy may be improved by incorporating an additional DOF, considering that even level walking in a straight line requires the ankle to function in both the sagittal and frontal planes. Additionally, normal daily activity includes more gait scenarios such as turning, traversing slopes, and adapting to uneven terrain profiles. To extend the design of ankle-foot control to the frontal plane, a better understanding of the multivariable mechanical impedance of the human ankle is needed.

Ankle mechanical impedance may provide an opportunity to better characterize ankle dynamics. Mechanical impedance of a dynamic system determines the evoked moment due to input motion perturbations and is a function of the stiffness, viscoelasticity, and inertia of the system. The ankle's mechanical impedance in a single DOF has been the focus of all prior studies, while multidirectional ankle characteristics have not been studied. Additionally, single-DOF ankle movements are rare in normal lower-limb actions, so control of multiple ankle DOFs presents unique challenges [22]. Therefore, understanding the ankle directional impedance during gait is a key factor for improving the design of lower-limb prostheses.

Powered prosthesis controllers are currently designed based on ankle moment-angle relationships that are averaged across a study population (e.g., Shamaei et al. [23]) rather than ankle impedance. Rouse et al. developed a platform capable of applying moment perturbations during the foot-flat stance phase in sagittal plane [24-25]. Mechanical ankle impedance in both DP and IE directions in non-load-bearing and stationary conditions was estimated by Rastgaar et al. for dynamic mechanical impedance [26-27] and Lee et al. for quasistatic mechanical impedance [28-31]. Ho et al. also studied the directional variation of quasistatic ankle mechanical impedance [32-33]. Further, Lee et al. developed a method for estimating time-varying mechanical impedance of ankle during the entire stride length for subjects 
walking on a treadmill [34]. Their study on nondisabled subjects showed consistent time-varying characteristics of ankle impedance during the entire stride in both sagittal and frontal planes.

In this article, ankle displacements and moments were studied during straight walking and sidestep cutting. The goal of this study is to show how the kinematics and kinetics of the ankle, and therefore its mechanical impedance, change in different maneuvers. The term sidestep cutting is used to describe the motion of pushing the body sideways using the leading leg to translate the body while walking forward (the motion is at or near $45^{\circ}$ from the original path) without rotating the body (e.g., stepping sideways to avoid an obstacle on the ground). The article describes experiments for collecting ankle kinematics and kinetics in the sagittal, frontal, and transverse planes during sidestep cutting and comparing the results with walking along a straight path.

\section{METHODS: ANKLE KINEMATICS AND KINETICS DURING GAIT}

To change direction during gait, one needs to perform different gait maneuvers such as a step turn, spin turn, or sidestep cutting. These maneuvers have different kinematics and kinetics. For example, compared with straight walking, step turns have considerably different velocity, length, and width and higher turning reaction forces $[1,14-15,17]$. Also, the ankle moment in the inversion direction is significantly different from the straight steps and spin turn steps [35].

A series of experiments were performed to quantify the ankle kinematics and kinetics behavior in the context of gait agility. The experiments measured the ankle kinematics and kinetics during stance phase of the sidestep cutting and compared the results with the ankle mechanics during straight walking. The study did not include any cognitive aspect of agility but focused on the ankle kinematics and kinetics due to change of direction and speed. Five male subjects with no self-reported neuromuscular and biomechanical disorders were recruited for the experiments (age: $23-27 \mathrm{yr}$, body mass index: $23-28 \mathrm{~kg} / \mathrm{m}^{2}$ ).

Hansen et al. described ankle moments in the sagittal plane during straight walking [18]. To calculate the ankle kinetics during walking, it was necessary to estimate the location of the ankle center of rotation, the reaction forces, and the moment arms for the reaction forces. The ankle is composed of the talocrural and the subtalar joints. It has been shown that the combined movement of both joints can be approximated as a monocentric single-DOF hinge joint for functional activities such as walking and running [36]. To identify the ankle center of rotation, the recommended definition by the International Society of Biomechanics (ISB) was used [37]. External markers were required to identify each joint because it is not possible to directly discern between the talocrural and the subtalar joints. The ankle center of rotation was approximated as the midpoint between the tip of the medial malleolus and the tip of the lateral malleolus for DP and external-internal rotation (EI). The approximation is also valid for IE at ankle neutral position when DP, IE, and EI angles are all zeroes [37]. In this article, dorsiflexion, inversion, and internal rotation were defined as positive rotations, similar to ISB definitions. Similarly, plantar flexion, eversion, and external rotation were defined as negative rotations. This notation is used throughout the article, where DP, IE, and EI are the foot rotations about the $x, y$, and $z$ axes of the foot coordinate system, respectively.

A motion-capture camera system was used to track the foot rotations and position of the ankle center. The motion-capture camera system consisted of eight OptiTrack Prime 17W cameras (NaturalPoint Inc; Corvallis, Oregon) in a square formation covering a volume of about $16 \mathrm{~m}^{3}$ and an area of $12 \mathrm{~m}^{2}$. The cameras emitted infrared light and captured the reflected light from reflectors mounted on the participants at a rate of $300 \mathrm{~Hz}$. Two reflective markers were placed on the participant, one at the tip of the medial malleolus and the other at the tip of the lateral malleolus. The markers' positions were recorded during the test, and the ankle center of rotation was estimated as the midpoint of the two markers in the global reference frame. Reflective markers were attached to two polycarbonate plastic rigid bodies developed by the camera system manufacturer to eliminate relative motion of the markers with respect to each other. One of the polycarbonate rigid bodies was attached to the participant's shoe above the metatarsal bones to record the global foot rotations. The second polycarbonate rigid body was attached to the participant's shin to record the global position of the shin. The ankle rotations were calculated as the relative rotations of the foot with respect to the shin.

Sidestep cutting maneuvers were initiated on the right foot. Two different gait speeds were studied and the results were compared with the straight steps for both left and right ankles. The slow speed was the preferred speed of gait of the participant (average of 96 steps/min). In the fast speed tests, the subjects were instructed to go as fast 
as they felt comfortable to perform sidestep cutting without occurrence of a flight phase (average of 114 steps/ min) [38]. The participants were instructed to start walking in a straight path from the outside of the field of view of the cameras. When they reached an obstacle on the ground, they performed a sidestep cutting to the left, pivoting about their right leg to avoid the obstacle and switching direction immediately, followed by a left-leg sidestep cutting that redirected the walk in a straight line parallel to the initial direction of gait (Figure 1). Similarly, straight walking tests were performed at slow and fast speeds, where each subject walked on a straight line stepping on the force plate. The straight walking tests were repeated for measuring the ground reaction forces for both the right and left feet at both slow and fast speeds (Figure 2(a) and (b), respectively). Each of the four different steps (left and right legs at straight walking and sidestep cutting) were repeated five times for each subject at both slow and fast speeds.

To measure the ground reaction forces, a Type 5233A force plate (Kistler Group; Winterthur, Switzerland) was used. The ground reaction forces in the $x, y$, and $z$ global axes (approximately pointing to the right, forward, and cephalad of the foot, respectively) were obtained directly from the force plate. The $z$ axis force, which was obtained from four individual load cells at each corner of the force plate, was also used to identify the location of the center of pressure of the foot when placed on the force plate. The origin of the force plate coordinate system was also the origin of the global coordinate system of the camera system. During the experiments, the data from the force plate were collected at 300 samples per second.

The distances between the ankle center of rotation and the center of pressure in the global coordinates, which were necessary for the estimation of the moment arms, were obtained directly from the marker positions in the global coordinate system. The displacements and the forces obtained in the global reference frame were transformed to the foot coordinate system using a rotation matrix. The rotation matrix was defined using the Euler angles describing the rotation of the foot (obtained from the markers placed on the rigid body on the subject's foot) relative to the global reference frame. Once the displacements and forces were transformed to the foot coordinate
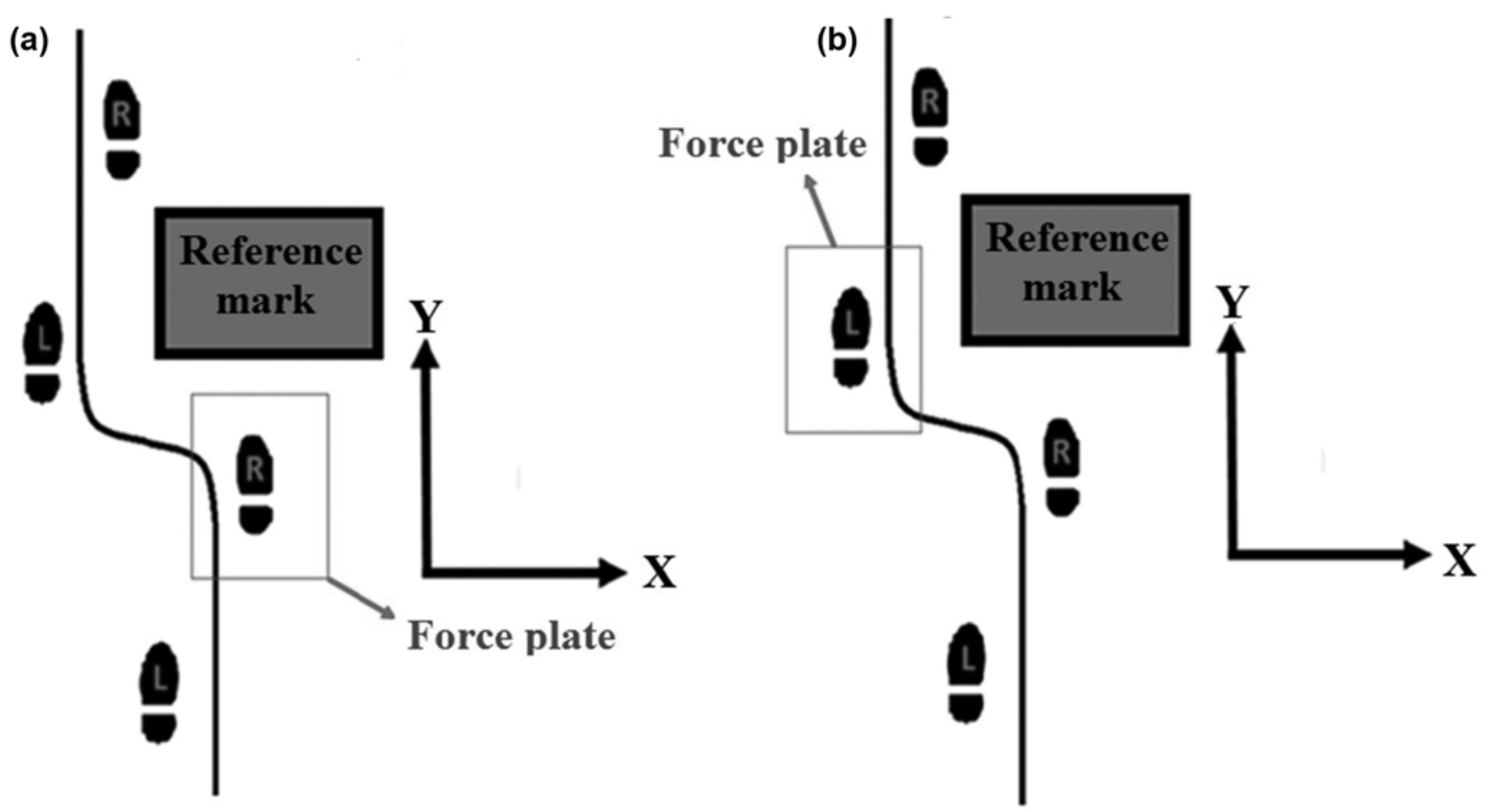

Figure 1.

Foot position during sidestep cutting. To record (a) right $(R)$ and (b) left $(L)$ foot ground reaction moments and ankle angles. 


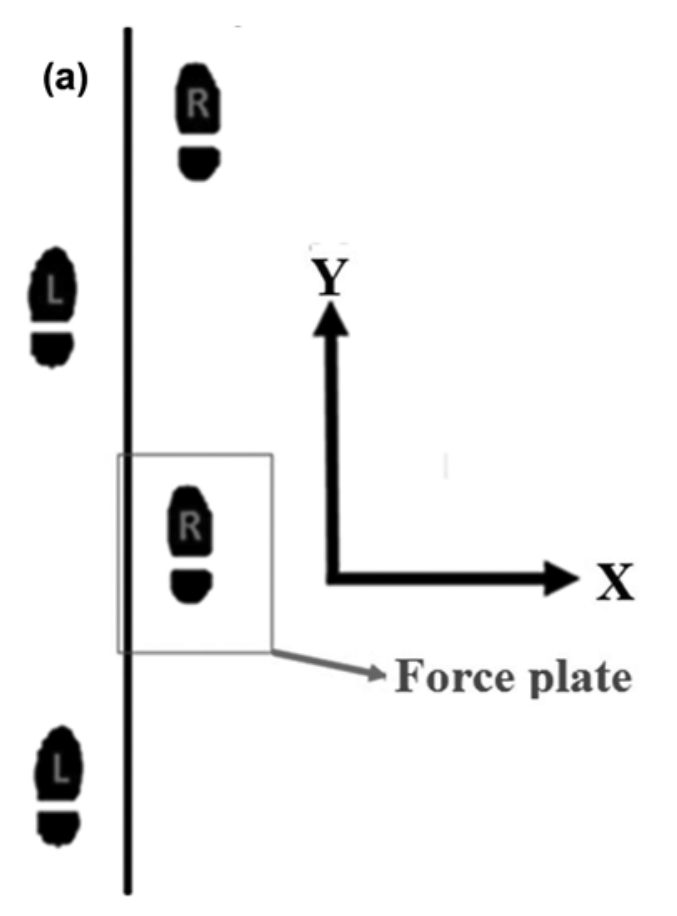

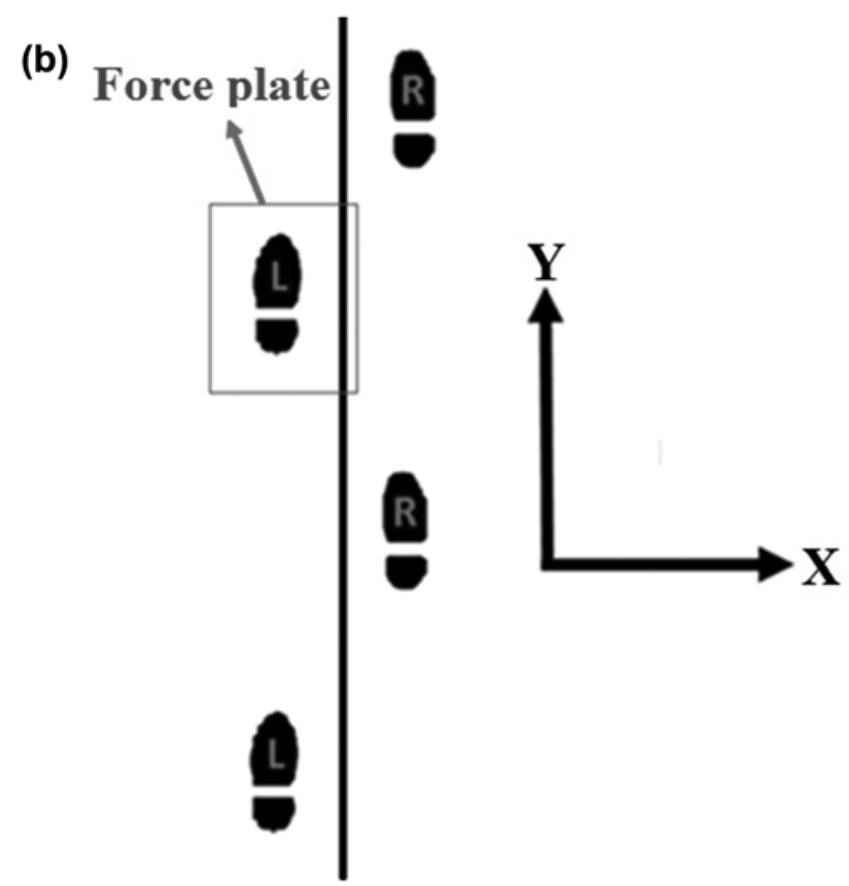

Figure 2.

Foot position during straight walking. To record (a) right $(R)$ and (b) left $(L)$ foot ground reaction moments and ankle angles.

system, the normalized moments (with respect to the subjects' body mass) were calculated. A view of the ground reaction forces and moment arms for calculations of the ankle moments in DP, IE, and EI can be seen in Figure 3(a), (b), and (c), respectively.

Three phases of the stance were identifiable using the data from the cameras and force plate. The weight acceptance (WA) phase started when the heel contacted the floor up to the point where the whole area of the foot was in contact with the floor. The mid-stance (MS) was identified as the entire duration that the foot was in full contact with the floor. The terminal stance and pre-swing (TP) phase was identified from the point where the heel stopped contacting the floor to the point where there was no contact between the foot and the floor. The subjects were weighed on the day of the test using the force plate and the moments were normalized with respect to the subject's weight. The moments and ankle angles at each stance period were calculated from the walking trials. The averages and standard errors of the angles and moments of the 25 entries for each step type were calculated (each of the 5 participants performed 5 trials of each step type). The changes in average moment and angle between the straight walking and sidestep cutting tests were calculated at each phase of the stance period (WA,
MS, and TP). One-way analysis of variance was used to compare the straight with turning step results to show whether their differences were statistically significant $(p<0.05)$.

\section{RESULTS AND DISCUSSION}

\section{Kinematics}

\section{Sagittal Plane}

No evident differences were observed in ankle kinematics in the sagittal plane (Figure 4). Tables 1 to 4 all show that there was no statistically significant difference between the right ankle kinematics in the sagittal plane during the different stance phases for straight walking and sidestep cutting at either slow or fast speeds.

\section{Frontal Plane}

The ankle kinematics in the frontal plane during sidestep cutting were significantly different from straight walking at both slow and fast speeds (Figure 5). During straight walking, the ankle rotations remained near constant. On the other hand, during the sidestep cutting, the right ankle showed a progressive inversion from a minimum rotation 
JRRD, Volume 52, Number 1, 2015
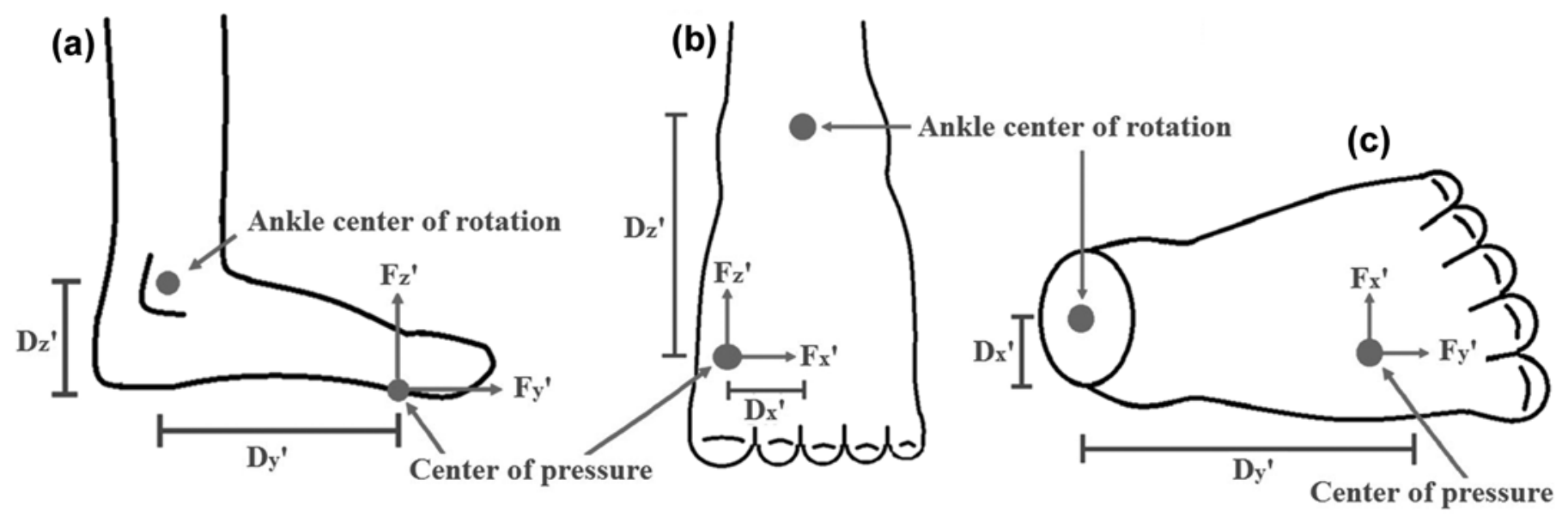

Figure 3.

(a) Foot schematics in sagittal plane showing ground reaction forces and moment arms for moment estimation in dorsiflexion-plantar flexion. (b) Foot schematics in coronal plane showing ground reaction forces and moment arms for moment estimation in inversioneversion. (c) Foot schematics in transverse plane showing ground reaction forces and moment arms for moment estimation in external-internal rotation. $D_{x}{ }^{\prime}=$ moment arm in $x$-axis of foot coordinate system, $D_{y}{ }^{\prime}=$ moment arm in $y$-axis of foot coordinate system, $\mathrm{D}_{z}{ }^{\prime}=$ moment arm in $z$-axis of foot coordinate system, $F_{x}{ }^{\prime}=$ ground reaction force in $x$-axis of foot coordinate system, $F_{y}{ }^{\prime}=$ ground reaction force in $y$-axis of foot coordinate system, $F_{z}^{\prime}=$ ground reaction force in $z$-axis of foot coordinate system.

(a)



(b)

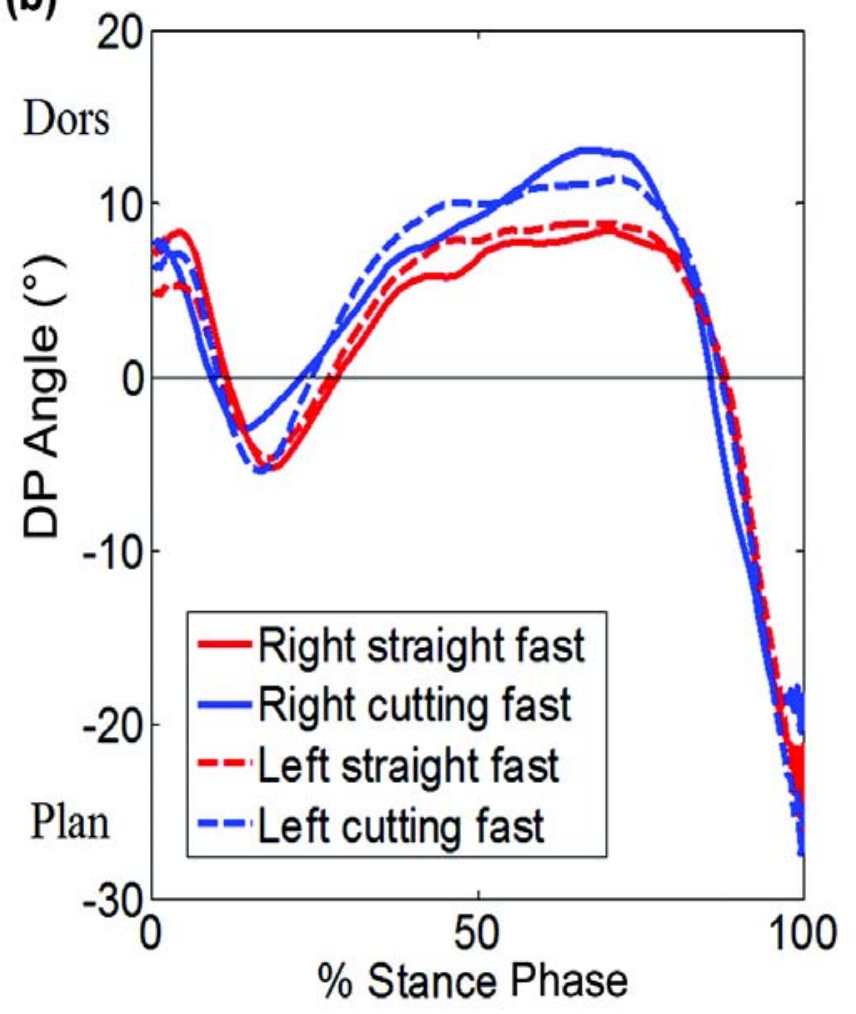

Figure 4.

(a) Plot of mean ankle angles in dorsiflexion-plantar flexion (DP) at slow speed. (b) Plot of mean ankle angles in DP at fast speed. Positive angles are dorsiflexion (Dors) and negative angles are plantar flexion (Plan). 
of $2^{\circ}$ and $3^{\circ}$ for slow and fast speeds, respectively, up to a maximum rotation of $13^{\circ}$ at both speeds. However, the left ankle started from near its maximum inversion of $8^{\circ}$ and $7^{\circ}$ for slow and fast speeds, respectively, and progressively rotated to the minimum rotation near $-4^{\circ}$ and $-3^{\circ}$ of eversion, respectively. This showed the significance of IE rotations to shift the body sideways during sidestep cutting.

Table 1 shows the details of the right ankle rotations during sidestep cutting and straight walking at slow speed. The frontal plane kinematics showed that the ankle was always in eversion during straight walking with the largest eversion at MS. This is expected because the body shifts from side to side during walking and shows the contribution of the ankle function in IE during straight walking. On the contrary, the ankle was in inversion during sidestep cutting. At WA, the mean right ankle rotation during straight walking was $-1^{\circ} \pm 0.8^{\circ}$ compared with $4^{\circ} \pm 0.6^{\circ}$ for sidestep cutting. At MS, these values were $-5^{\circ} \pm 0.3^{\circ}$ and $4^{\circ} \pm 0.6^{\circ}$, respectively. The most significant change occurred during TP, where the mean rotation of the ankle during straight walking was $-3^{\circ} \pm 0.5^{\circ}$ compared with $11^{\circ} \pm 1.0^{\circ}$ during sidestep cutting.

The results of the comparison of the different stance phases during fast speed were close to the results of the slow speed experiment (Table 2). Similar to the slow speed, there were statistically significant differences in ankle rotation at WA, MS, and TP between sidestep cutting and straight walking. At WA, the mean right ankle rotation during straight walking was $-3^{\circ} \pm 0.8^{\circ}$ compared with $5^{\circ} \pm 0.7^{\circ}$ for sidestep cutting. At MS, these values were $-4^{\circ} \pm 0.4^{\circ}$ and $6^{\circ} \pm 0.5^{\circ}$, respectively. The mean rotation of the ankle at straight walking was $-4^{\circ} \pm 0.6^{\circ}$ compared with $10^{\circ} \pm 0.7^{\circ}$ during sidestep cutting. It can be seen that the ankle rotations between the slow speed and the associated fast speed phases did not change substantially. The changes in the IE angle were significant during the sidestep cutting from straight walking, where the ankle, at slow speed, showed an increased inversion of $5^{\circ}$ at WA, $9^{\circ}$ at MS, and $14^{\circ}$ at TP; at fast speed these values were $8^{\circ}, 10^{\circ}$, and $14^{\circ}$, respectively.

For the ankle rotations in the left leg, there were statistically significant differences between all the phases of straight walking and sidestep cutting at fast speed (Table 4). In the slow speed experiment, only MS and WA of straight walking and sidestep cutting were significantly different (Table 3). Similar to the right ankle results, the ankle was in inversion during all the phases of sidestep cutting. The maximum average inversion during sidestep cutting occurred at WA with $8^{\circ} \pm 0.8^{\circ}$ at slow speed and $7^{\circ} \pm 1.0^{\circ}$ at fast speed.

\section{Transverse Plane}

The TP angles peaked between $10^{\circ}$ and $15^{\circ}$ of internal rotation in all tests except the right-leg sidestep cutting at both slow and fast speeds (Figure 6). The peak external rotation at slow speed was $4^{\circ}$ and at fast speed was $5^{\circ}$. During straight walking and the left-leg sidestep

Table 1.

Right ankle normalized moments and angles during stance period of straight walking and sidestep cutting at slow speed. Positive angles are dorsiflexion, inversion, and internal rotation for dorsiflexion-plantar flexion (DP), inversion-eversion (IE), and external-internal rotation (EI), respectively.

\begin{tabular}{|c|c|c|c|c|c|c|c|c|}
\hline $\begin{array}{l}\text { Right } \\
\text { Slow }\end{array}$ & $\begin{array}{c}\text { Torque Straight } \\
\text { Walking }(\mathrm{Nm} / \mathrm{kg}) \\
\text { (mean } \pm \mathrm{SE})\end{array}$ & $\begin{array}{c}\text { Torque Sidestep } \\
\text { Cutting }(\mathrm{Nm} / \mathrm{kg}) \\
(\text { mean } \pm \mathrm{SE})\end{array}$ & $\begin{array}{l}\text { Change in } \\
\text { Torque } \\
(\mathrm{Nm} / \mathrm{kg})\end{array}$ & $\begin{array}{c}\text { Torque } \\
p \text {-Value }\end{array}$ & $\begin{array}{c}\text { Angle Straight } \\
\text { Walking }\left({ }^{\circ}\right) \\
\text { (mean } \pm \text { SE) }\end{array}$ & $\begin{array}{l}\text { Angle Sidestep } \\
\text { Cutting }\left(^{\circ}\right) \\
\text { (mean } \pm \text { SE) }\end{array}$ & $\begin{array}{l}\text { Change in } \\
\text { Angle }\left(^{\circ}\right)\end{array}$ & $\begin{array}{c}\text { Angle } \\
p \text {-Value }\end{array}$ \\
\hline \multicolumn{9}{|l|}{$\overline{\mathrm{DP}}$} \\
\hline MS & $-0.67 \pm 0.02$ & $-0.56 \pm 0.04$ & 0.11 & 0.06 & $3 \pm 0.8$ & $4 \pm 0.9$ & 1 & 0.40 \\
\hline $\mathrm{TP}$ & $-1.03 \pm 0.04$ & $-1.07 \pm 0.03$ & -0.04 & 0.36 & $4 \pm 0.8$ & $4 \pm 0.7$ & 0 & 0.74 \\
\hline \multicolumn{9}{|c|}{ IE } \\
\hline MS & $-0.19 \pm 0.02$ & $-0.29 \pm 0.03$ & -0.10 & $0.00^{*}$ & $-5 \pm 0.3$ & $4 \pm 0.6$ & 9 & $0.00^{*}$ \\
\hline $\mathrm{TP}$ & $-0.16 \pm 0.02$ & $-0.15 \pm 0.04$ & 0.01 & 0.86 & $-3 \pm 0.5$ & $11 \pm 1.0$ & 14 & $0.00^{*}$ \\
\hline \multicolumn{9}{|c|}{ EI } \\
\hline WA & $-0.01 \pm 0.00$ & $0.02 \pm 0.00$ & 0.03 & $0.00^{*}$ & $-3 \pm 0.8$ & $-5 \pm 0.7$ & -1 & 0.21 \\
\hline MS & $-0.02 \pm 0.00$ & $-0.05 \pm 0.00$ & -0.03 & $0.00^{*}$ & $-3 \pm 0.9$ & $-1 \pm 1.0$ & 2 & 0.13 \\
\hline $\mathrm{TP}$ & $-0.04 \pm 0.00$ & $-0.25 \pm 0.01$ & -0.21 & $0.00^{*}$ & $1 \pm 0.9$ & $2 \pm 1.3$ & 0.4 & 0.81 \\
\hline
\end{tabular}


Table 2.

Right ankle normalized moments and angles during stance period of straight walking and sidestep cutting at fast speed. Positive angle are dorsiflexion, inversion, and internal rotation for dorsiflexion-plantar flexion (DP), inversion-eversion (IE), and external-internal rotation (EI), respectively.

\begin{tabular}{|c|c|c|c|c|c|c|c|c|}
\hline $\begin{array}{c}\text { Right } \\
\text { Fast }\end{array}$ & $\begin{array}{c}\text { Torque Straight } \\
\text { Walking }(\mathrm{Nm} / \mathrm{kg}) \\
\text { (mean } \pm \mathrm{SE})\end{array}$ & $\begin{array}{c}\text { Torque Sidestep } \\
\text { Cutting }(\mathrm{Nm} / \mathrm{kg}) \\
\text { (mean } \pm \mathrm{SE})\end{array}$ & $\begin{array}{l}\text { Change in } \\
\text { Torque } \\
\text { (Nm/kg) }\end{array}$ & $\begin{array}{l}\text { Torque } \\
p \text {-Value }\end{array}$ & $\begin{array}{l}\text { Angle Straight } \\
\text { Walking }\left(^{\circ}\right) \\
(\text { mean } \pm \text { SE) }\end{array}$ & $\begin{array}{c}\text { Angle Sidestep } \\
\text { Cutting }\left(^{\circ}\right) \\
\text { (mean } \pm \text { SE) } \\
\end{array}$ & $\begin{array}{l}\text { Change in } \\
\text { Angle }\left({ }^{\circ}\right)\end{array}$ & $\begin{array}{c}\text { Angle } \\
p \text {-Value }\end{array}$ \\
\hline \multicolumn{9}{|l|}{$\overline{\mathrm{DP}}$} \\
\hline WA & $0.64 \pm 0.04$ & $0.53 \pm 0.05$ & -0.10 & 0.10 & $2 \pm 1.5$ & $1 \pm 1.3$ & 0 & 0.82 \\
\hline MS & $-0.47 \pm 0.03$ & $-0.42 \pm 0.03$ & 0.05 & 0.24 & $4 \pm 0.8$ & $6 \pm 0.7$ & 2 & 0.06 \\
\hline $\mathrm{TP}$ & $-1.15 \pm 0.04$ & $-1.16 \pm 0.04$ & -0.01 & 0.80 & $0 \pm 0.9$ & $2 \pm 1.2$ & 2 & 0.20 \\
\hline \multicolumn{9}{|l|}{ EI } \\
\hline WA & $-0.05 \pm 0.02$ & $-0.21 \pm 0.02$ & -0.15 & $0.00^{*}$ & $-3 \pm 0.8$ & $5 \pm 0.7$ & 8 & $0.00^{*}$ \\
\hline MS & $-0.18 \pm 0.01$ & $-0.31 \pm 0.02$ & -0.13 & $0.00^{*}$ & $-4 \pm 0.4$ & $6 \pm 0.5$ & 10 & $0.00^{*}$ \\
\hline $\mathrm{TP}$ & $-0.17 \pm 0.02$ & $-0.15 \pm 0.03$ & 0.03 & 0.51 & $-4 \pm 0.6$ & $10 \pm 0.7$ & 14 & $0.00^{*}$ \\
\hline \multicolumn{9}{|l|}{ IE } \\
\hline WA & $-0.01 \pm 0.01$ & $0.06 \pm 0.01$ & 0.07 & $0.00^{*}$ & $-4 \pm 0.8$ & $-5 \pm 0.8$ & -1 & 0.49 \\
\hline MS & $-0.01 \pm 0.00$ & $-0.04 \pm 0.00$ & -0.03 & $0.00^{*}$ & $-4 \pm 0.7$ & $-2 \pm 0.9$ & 2 & 0.05 \\
\hline $\mathrm{TP}$ & $-0.05 \pm 0.01$ & $-0.28 \pm 0.01$ & -0.23 & $0.00^{*}$ & $2 \pm 0.8$ & $2 \pm 1.3$ & 0 & 0.95 \\
\hline
\end{tabular}

${ }^{*}$ Statistically significant difference between straight walking and sidestep cutting $(p<0.05)$.

MS = mid-stance, SE = standard error, TP = terminal stance and pre-swing, WA = weight acceptance.

Table 3.

Left ankle normalized moments and angles during stance period of straight walking and sidestep cutting at slow speed. Positive angles are dorsiflexion, inversion, and internal rotation for dorsiflexion-plantar flexion (DP), inversion-eversion (IE), and external-internal rotation (EI), respectively.

\begin{tabular}{|c|c|c|c|c|c|c|c|c|}
\hline $\begin{array}{l}\text { Left } \\
\text { Slow }\end{array}$ & $\begin{array}{c}\text { Torque Straight } \\
\text { Walking }(\mathrm{Nm} / \mathrm{kg}) \\
\text { (mean } \pm \mathrm{SE})\end{array}$ & $\begin{array}{c}\text { Torque Sidestep } \\
\text { Cutting }(\mathrm{Nm} / \mathrm{kg}) \\
\text { (mean } \pm \mathrm{SE})\end{array}$ & $\begin{array}{l}\text { Change in } \\
\text { Torque } \\
(\mathrm{Nm} / \mathrm{kg})\end{array}$ & $\begin{array}{l}\text { Torque } \\
p \text {-Value }\end{array}$ & $\begin{array}{c}\text { Angle Straight } \\
\text { Walking }\left({ }^{\circ}\right) \\
(\text { mean } \pm \text { SE) }\end{array}$ & $\begin{array}{c}\text { Angle Sidestep } \\
\text { Cutting }\left(^{\circ}\right) \\
(\text { mean } \pm \text { SE) }\end{array}$ & $\begin{array}{c}\text { Change in } \\
\text { Angle }\left({ }^{\circ}\right)\end{array}$ & $\begin{array}{c}\text { Angle } \\
p \text {-Value }\end{array}$ \\
\hline \multicolumn{9}{|l|}{$\overline{\mathrm{DP}}$} \\
\hline WA & $0.26 \pm 0.02$ & $0.33 \pm 0.02$ & 0.06 & $0.03^{*}$ & $-3 \pm 0.7$ & $-1 \pm 0.9$ & 2 & 0.10 \\
\hline MS & $-0.68 \pm 0.03$ & $-0.62 \pm 0.06$ & 0.06 & 0.34 & $3 \pm 0.7$ & $5 \pm 0.8$ & 2 & 0.09 \\
\hline $\mathrm{TP}$ & $-1.07 \pm 0.03$ & $-1.12 \pm 0.03$ & -0.05 & 0.29 & $3 \pm 1.1$ & $1 \pm 1.7$ & -2 & 0.32 \\
\hline \multicolumn{9}{|l|}{ EI } \\
\hline WA & $-0.07 \pm 0.01$ & $-0.05 \pm 0.02$ & 0.01 & 0.61 & $2 \pm 1.0$ & $8 \pm 0.8$ & 6 & $0.00^{*}$ \\
\hline MS & $-0.14 \pm 0.02$ & $-0.21 \pm 0.02$ & -0.07 & $0.01^{*}$ & $-1 \pm 0.7$ & $3 \pm 0.5$ & 5 & $0.00^{*}$ \\
\hline TP & $-0.08 \pm 0.02$ & $-0.13 \pm 0.02$ & -0.05 & 0.11 & $-1 \pm 0.5$ & $0 \pm 0.6$ & 1 & 0.27 \\
\hline \multicolumn{9}{|l|}{ IE } \\
\hline WA & $0.00 \pm 0.00$ & $0.04 \pm 0.00$ & 0.04 & $0.00^{*}$ & $-5 \pm 0.4$ & $-8 \pm 0.6$ & -2 & 0.00 \\
\hline MS & $-0.02 \pm 0.00$ & $-0.04 \pm 0.01$ & -0.02 & $0.01^{*}$ & $-5 \pm 0.7$ & $-3 \pm 0.8$ & 1 & 0.32 \\
\hline $\mathrm{TP}$ & $-0.04 \pm 0.01$ & $-0.06 \pm 0.01$ & -0.02 & 0.09 & $2 \pm 0.7$ & $4 \pm 0.7$ & 1 & 0.14 \\
\hline
\end{tabular}

${ }^{*}$ Statistically significant difference between straight walking and sidestep cutting $(p<0.05)$.

MS = mid-stance, $\mathrm{SE}=$ standard error, $\mathrm{TP}=$ terminal stance and pre-swing, WA = weight acceptance.

cutting, the participants pivoted on top of the standing leg to align the next step directly in front of them to maintain the forward path and thus generating the observed internal rotation. During the right-leg sidestep cutting, the left-leg cutting step that follows the right-leg cutting step (Figure 1) was not directly in front of the subject, but offset to the left. This caused the observed external rotation at the TP of the right-ankle sidestep cutting.

The transverse plane rotations at sidestep cutting and straight walking were not significantly different, except at the left-ankle WA at both speeds. The ankle transverse plane rotation at WA and slow speed were $-5^{\circ} \pm 0.4^{\circ}$ for straight walking and $-8 \pm 0.6^{\circ}$ for sidestep cutting. At fast speed, these values were $-6^{\circ} \pm 0.4^{\circ}$ and $-9 \pm 0.6^{\circ}$, respectively.

\section{Kinetics}

\section{Sagittal Plane}

The major difference among the different steps is that the dorsiflexion moment at WA was about twice as large during the fast walking tests compared with the slow walking tests, either during straight walking or sidestep cutting (Figure 7). This was due to larger contact forces of the foot with the ground as expected in faster walking 
Table 4.

Left ankle normalized moments and angles during stance period of straight walking and sidestep cutting at fast speed. Positive angles are dorsiflexion, inversion, and internal rotation for dorsiflexion-plantar flexion (DP), inversion-eversion (IE), and external-internal rotation (EI), respectively.

\begin{tabular}{|c|c|c|c|c|c|c|c|c|}
\hline $\begin{array}{l}\text { Left } \\
\text { Fast }\end{array}$ & $\begin{array}{c}\text { Torque Straight } \\
\text { Walking }(\mathrm{Nm} / \mathrm{kg}) \\
\text { (mean } \pm \mathrm{SE})\end{array}$ & $\begin{array}{c}\text { Torque Sidestep } \\
\text { Cutting }(\mathrm{Nm} / \mathrm{kg}) \\
\text { (mean } \pm \mathrm{SE})\end{array}$ & $\begin{array}{c}\text { Change in } \\
\text { Torque } \\
\text { (Nm/kg) }\end{array}$ & $\begin{array}{c}\text { Torque } \\
p \text {-Value }\end{array}$ & $\begin{array}{c}\text { Angle Straight } \\
\text { Walking }\left(^{\circ}\right) \\
\text { (mean } \pm \text { SE) }\end{array}$ & $\begin{array}{c}\text { Angle Sidestep } \\
\text { Cutting }\left(^{\circ}\right) \\
\text { (mean } \pm \text { SE) }\end{array}$ & $\begin{array}{c}\text { Change in } \\
\text { Angle }\left(^{\circ}\right)\end{array}$ & $\begin{array}{c}\text { Angle } \\
p \text {-Value }\end{array}$ \\
\hline \multicolumn{9}{|l|}{$\overline{\mathrm{DP}}$} \\
\hline MS & $-0.51 \pm 0.04$ & $-0.58 \pm 0.05$ & -0.07 & 0.28 & $5 \pm 0.7$ & $7 \pm 0.8$ & 2 & 0.05 \\
\hline $\mathrm{TP}$ & $-1.15 \pm 0.03$ & $-1.11 \pm 0.02$ & 0.05 & 0.18 & $0 \pm 1.6$ & $-1 \pm 1.7$ & -1 & 0.82 \\
\hline \multicolumn{9}{|l|}{ EI } \\
\hline MS & $-0.12 \pm 0.01$ & $-0.22 \pm 0.02$ & -0.10 & $0.00^{*}$ & $-1 \pm 0.7$ & $5 \pm 0.7$ & 6 & $0.00^{*}$ \\
\hline TP & $-0.08 \pm 0.02$ & $-0.11 \pm 0.02$ & -0.03 & 0.30 & $-2 \pm 0.5$ & $1 \pm 0.9$ & 2 & $0.02^{*}$ \\
\hline \multicolumn{9}{|l|}{$\mathrm{IE}$} \\
\hline WA & $-0.01 \pm 0.01$ & $0.08 \pm 0.1$ & 0.08 & $0.00^{*}$ & $-6 \pm 0.4$ & $-9 \pm 0.6$ & -3 & $0.00^{*}$ \\
\hline MS & $-0.01 \pm 0.00$ & $-0.04 \pm 0.01$ & -0.03 & $0.00^{*}$ & $-6 \pm 0.9$ & $-5 \pm 0.9$ & 1 & 0.32 \\
\hline TP & $-0.04 \pm 0.01$ & $-0.08 \pm 0.02$ & -0.04 & $0.02^{*}$ & $2 \pm 0.8$ & $3 \pm 0.9$ & 1 & 0.54 \\
\hline
\end{tabular}

speeds. During MS and TP, however, the differences were not as pronounced as WA. The maximum dorsiflexion moment for the right ankle during sidestep cutting at slow speed was $0.47 \pm 0.04 \mathrm{Nm} / \mathrm{kg}$ and at fast speed was $0.57 \pm 0.07 \mathrm{Nm} / \mathrm{kg}$. These values for the left ankle were $0.53 \pm 0.02 \mathrm{Nm} / \mathrm{kg}$ and $0.96 \pm 0.03 \mathrm{Nm} / \mathrm{kg}$, respectively.

During sidestep cutting at slow speeds, the right step shifts the body to the left to avoid the obstacle on the ground. There was no statistically significant difference between DP moments at the different phases of stance period between straight walking and sidestep cutting (Table 1). At WA, the mean moment values were $0.31 \pm$ $0.03 \mathrm{Nm} / \mathrm{kg}$ and $0.33 \pm 0.02 \mathrm{Nm} / \mathrm{kg}$ for straight walking and sidestep cutting at slow speed, respectively. At MS, those values were $-0.67 \pm 0.02 \mathrm{Nm} / \mathrm{kg}$ and $-0.56 \pm$ $0.04 \mathrm{Nm} / \mathrm{kg}$, respectively, and for TP they were $-1.03 \pm$ $0.04 \mathrm{Nm} / \mathrm{kg}$ and $-1.07 \pm 0.03 \mathrm{Nm} / \mathrm{kg}$, respectively. We observed that the mean moment at TP was greater than MS and WA in both sidestep cutting and straight walking.

There was no statistically significant difference between DP moments at the different phases of stance period of straight walking and sidestep cutting at fast speeds (Table 2). The maximum average moment occurred at TP, with $-1.15 \pm 0.04 \mathrm{Nm} / \mathrm{kg}$ at straight walking and $-1.16 \pm 0.04 \mathrm{Nm} / \mathrm{kg}$ at sidestep cutting.

During sidestep cutting, the left step following the right-foot cutting step redirects the body to the original walking direction. There was a statistically significant difference in the sagittal plane moments at WA during straight walking and sidestep cutting at slow speed (Table $3)$. The corresponding moment values were $0.26 \pm$ $0.02 \mathrm{Nm} / \mathrm{kg}$ at the WA of straight walking and $0.33 \pm$ $0.02 \mathrm{Nm} / \mathrm{kg}$ for sidestep cutting. There was no statistically significant difference between sagittal plane moments at MS and TP phases of stance for straight walking compared with sidestep cutting. At MS, the mean moment values were $-0.68 \pm 0.03 \mathrm{Nm} / \mathrm{kg}$ and $-0.62 \pm 0.06 \mathrm{Nm} / \mathrm{kg}$ for straight walking and sidestep cutting, respectively, at slow speed. These values for TP were $-1.07 \pm 0.03 \mathrm{Nm} / \mathrm{kg}$ and $-1.12 \pm 0.03 \mathrm{Nm} / \mathrm{kg}$, respectively. The mean moment at TP was greater than MS and WA, in both sidestep cutting and straight walking, as we expected.

There was no statistically significant difference between DP moments at WA, MS, and TP phases of the stance periods during straight walking and sidestep cutting at fast speeds (Table 4). At WA, the mean moment values were $0.51 \pm 0.03 \mathrm{Nm} / \mathrm{kg}$ and $0.51 \pm 0.02 \mathrm{Nm} / \mathrm{kg}$ for straight walking and sidestep cutting, respectively. For MS, those values were $-0.51 \pm 0.04 \mathrm{Nm} / \mathrm{kg}$ and $-0.58 \pm$ $0.05 \mathrm{Nm} / \mathrm{kg}$, respectively, and for TP were $-1.15 \pm$ $0.03 \mathrm{Nm} / \mathrm{kg}$ and $-1.11 \pm 0.02 \mathrm{Nm} / \mathrm{kg}$, respectively. The mean moment at TP was greater than MS and WA in both sidestep cutting and straight walking.

\section{Frontal Plane}

The maximum eversion moments during sidestep cutting were higher than the corresponding straight walking with similar speeds (Figure 8). The maximum eversion 



Figure 5.

(a) Plot of mean ankle angles in inversion-eversion (IE) at slow speed. (b) Plot of mean ankle moments in IE at fast speed. Positive angles are inversion (Inv) and negative angles are eversion (Eve).

moments for the right and left steps in sidestep cutting occurred at approximately 25 percent of stance. The maximum eversion moment for the right ankle during sidestep cutting at slow speed was $0.36 \pm 0.02 \mathrm{Nm} / \mathrm{kg}$ and at fast speed was $0.45 \pm 0.02 \mathrm{Nm} / \mathrm{kg}$. These values were $0.29 \pm$ $0.02 \mathrm{Nm} / \mathrm{kg}$ and $0.38 \pm 0.02 \mathrm{Nm} / \mathrm{kg}$ for the left ankle, respectively.

During both sidestep cutting and straight walking at slow speeds, the IE moments were always in the eversion direction (Table 1). There was a statistically significant increase in eversion moments at WA and MS during sidestep cutting compared with straight walking. At WA, the mean moment values were $-0.04 \pm 0.01 \mathrm{Nm} / \mathrm{kg}$ and $-0.11 \pm$ $0.02 \mathrm{Nm} / \mathrm{kg}$ for straight walking and sidestep cutting, respectively. At MS, those values were $-0.19 \pm 0.02 \mathrm{Nm} / \mathrm{kg}$ and $-0.29 \pm 0.03 \mathrm{Nm} / \mathrm{kg}$, respectively. The mean moments at TP in sidestep cutting and straight walking were not statistically different. At TP, the mean moment values decreased slightly to $-0.16 \pm 0.02 \mathrm{Nm} / \mathrm{kg}$ and $-0.15 \pm 0.04$ $\mathrm{Nm} / \mathrm{kg}$ for sidestep cutting and straight walking, respectively. The results of the comparison of the different stance phases during fast speeds were close to the results of the slow speed experiment. The difference in ankle moments between sidestep cutting and straight walking at WA and MS and fast speed was statistically significant (Table 2). Also, the mean moments were close to slow speed results for each experiment.

In the left step, the maximum average IE moment occurred at MS in both straight walking and sidestep cutting. There was a statistically significant difference between the IE moments in straight walking and sidestep cutting at both slow and fast speeds. At slow speed, the maximum average IE moment occurred in MS with values of $-0.14 \pm 0.02 \mathrm{Nm} / \mathrm{kg}$ for straight walking and $-0.21 \pm$ $0.02 \mathrm{Nm} / \mathrm{kg}$ for sidestep cutting (Table 3). At fast speed, these values were $-0.12 \pm 0.01 \mathrm{Nm} / \mathrm{kg}$ for straight walking and $-0.22 \pm 0.02 \mathrm{Nm} / \mathrm{kg}$ for sidestep cutting, showing no significant change from slow speed results (Table 4).

\section{Transverse Plane}

The right ankle showed a large increase in external moments at the TP of sidestep cutting (Figure 9). EI moments were significantly different between straight walking and sidestep cutting for the right ankle, although the average angles were statistically the same. The transverse plane moments during the WA and MS were small 



Figure 6.

(a) Plot of mean ankle angles in external-internal rotation (El) at slow speed. (b) Plot of mean ankle angles in El at fast speed. Positive angles are internal rotation (Int) and negative angles are external rotation (Ext).
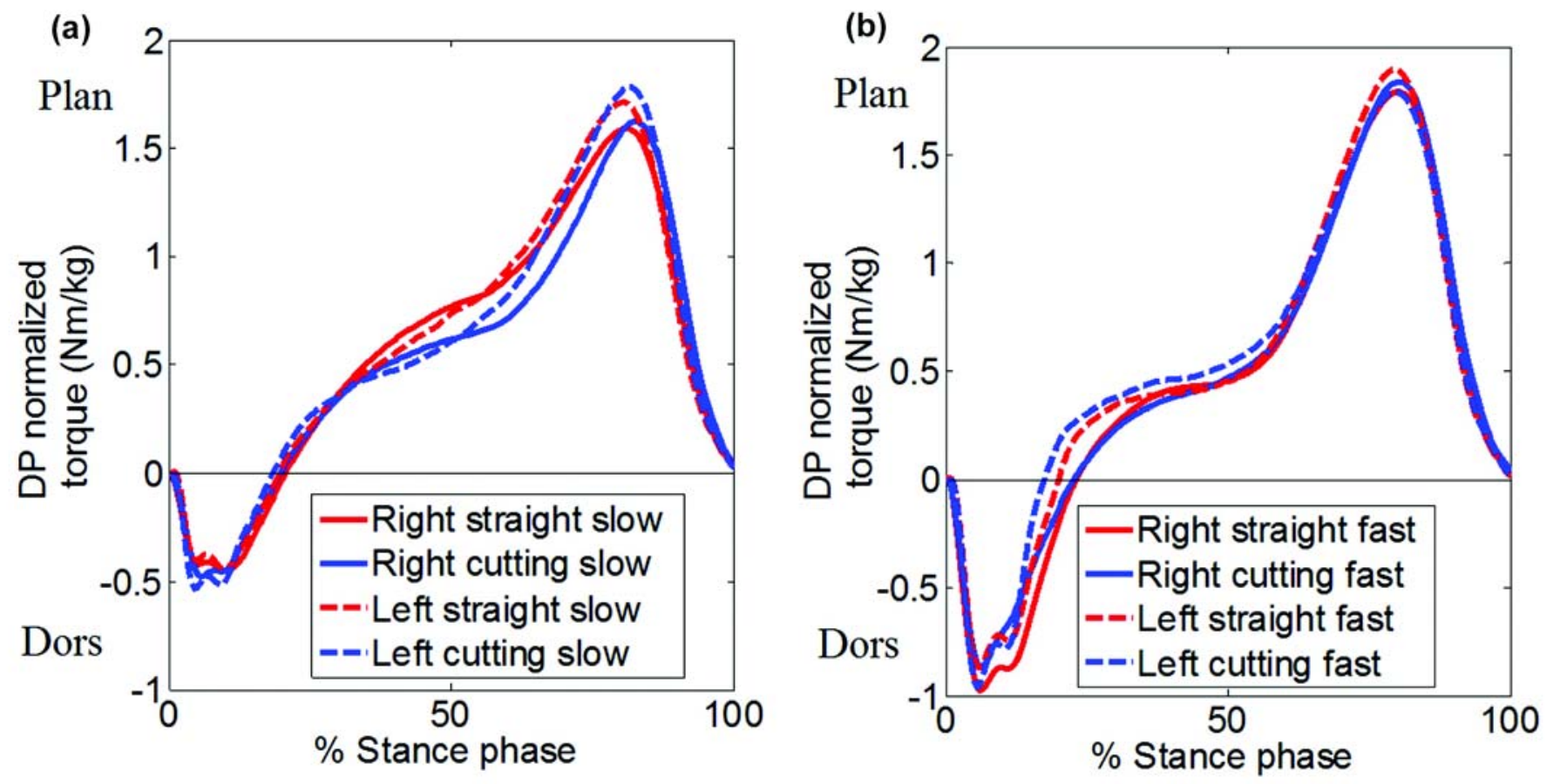

Figure 7.

(a) Plot of mean normalized ankle moments in dorsiflexion-plantar flexion (DP) at slow speed. (b) Plot of mean normalized ankle moments in DP at fast speed. Positive moments are plantar flexion (Plan) and negative moments are dorsiflexion (Dors). 
(a)

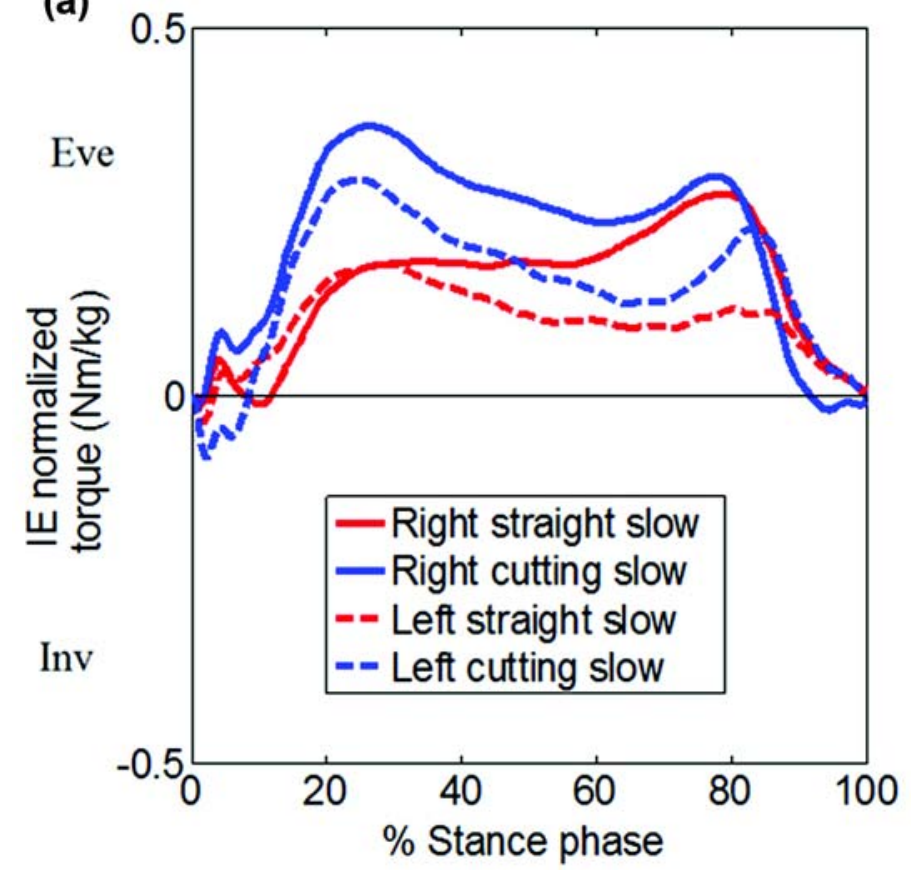

(b)

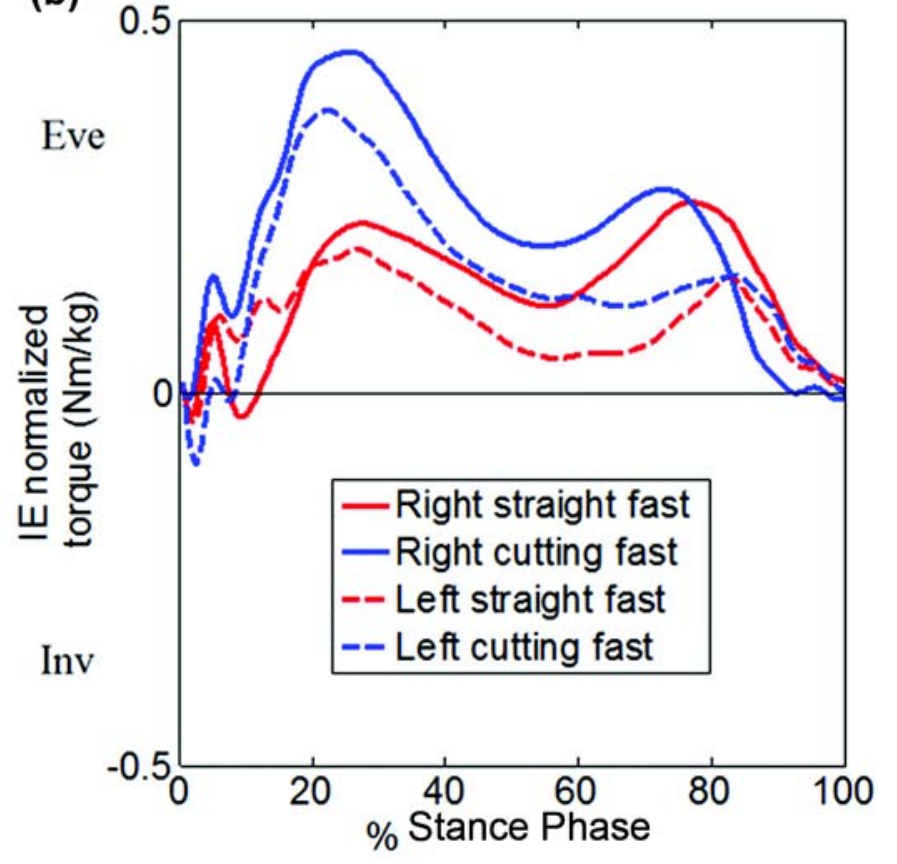

Figure 8.

(a) Plot of mean normalized ankle moments in inversion-eversion (IE) at slow speed. (b) Plot of mean normalized ankle moments in IE at fast speed. Positive moments are inversion (Inv) and negative moments are eversion (Eve).

when compared with the sagittal and frontal plane moments and never became greater than $0.12 \mathrm{Nm} / \mathrm{kg}$. However, at TP during sidestep cutting, the external moment increased to a maximum of $0.38 \pm 0.02 \mathrm{Nm} / \mathrm{kg}$ and $0.44 \pm 0.03 \mathrm{Nm} / \mathrm{kg}$ for the slow and fast speeds, respectively. Note that one of the challenges is that the hip joint also contributes to the transverse plane moments and that the measured moments were the resultant moment generated by the hip and ankle. However, the measured transverse plane rotations were estimated as the relative movement of the foot with respect to the lower leg. Further investigation is required to quantify the contribution of the hip and ankle to the transverse plane moments during the push-off.

All the moments were statistically significantly different when comparing straight walking with sidestep cutting at all the phases of the steps in both the slow and fast speed experiments. While the rotation moments for sidestep cutting were generally greater than straight walking at the corresponding speeds, they were significantly smaller than the sagittal and frontal plane moments at the corresponding stance phase.

\section{Remarks on Ankle Impedance}

The ankle mechanics during sidestep cutting and straight walking at two different speeds showed that the ankle frontal plane rotation significantly changed during sidestep cutting when compared with straight walking. The data showed that during the right cutting step, increased eversion moment occurred at the WA and MS phases compared with straight walking. Similarly, an increased inversion was observed resulting from body leaning to the inside of the turn. While the body was leaning, the body weight generated a net moment to continually lean the body and increased the inversion angle, although the ankle torque was in eversion acting as a braking moment opposing the motion. At the end of the right cutting step, the subjects immediately rotated and leaned their bodies to the right before the WA of the left foot. When the left foot contacted the ground, it stopped the lateral motion of the body followed by the rotation of the body back to vertical position. This caused the left ankle to move from inversion back to a near neutral position without the need of increased eversion moments.

Analysis of the ankle mechanics implies that the change of ankle impedance depends on the walking 

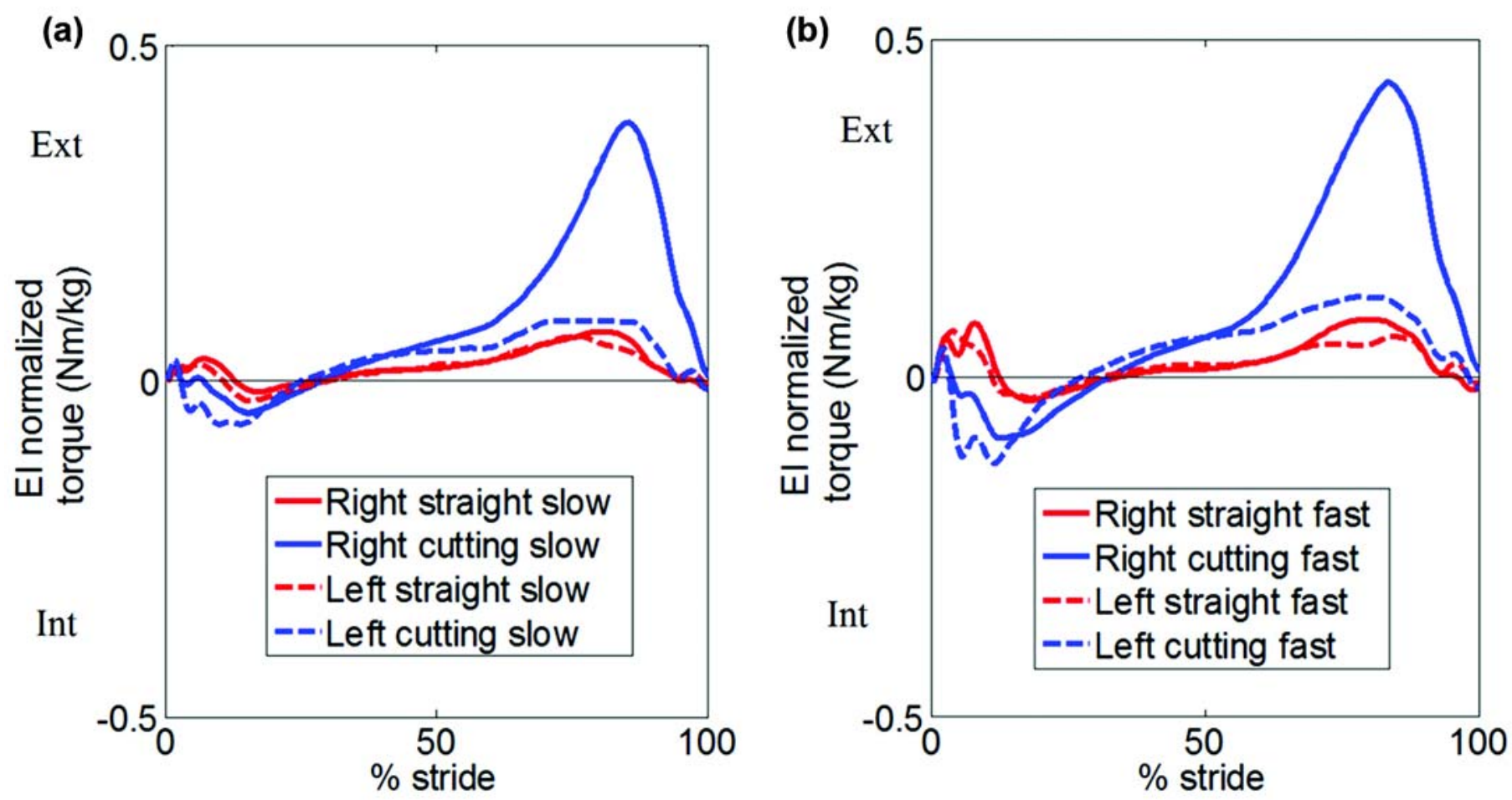

Figure 9.

(a) Plot of mean normalized ankle moments in external-internal rotation (EI) at slow speed. (b) Plot of mean normalized ankle moments in El at fast speed. Positive moments are external rotation (Ext) and negative moments are internal rotation (Int).

conditions. An impedance function maps the time-history of ankle kinematics into the appropriate time-history of ankle kinetics. If the change in ankle kinematics increases while there is no change or a decrease in ankle kinetics, the ankle impedance has decreased since more displacement was generated with the same or less moment. This was observed in frontal plane (i.e., IE motion) at the TP of the right ankle and at the WA of the left ankle at both speeds during sidestep cutting. At the TP of the right ankle at both speeds, the change in moment from straight walking to sidestep cutting was near $0 \mathrm{Nm} / \mathrm{kg}$, while the change in angle was $14^{\circ}$. At the WA of the left angle at both speeds, the change in moment from straight walking to sidestep cutting was near $0 \mathrm{Nm} / \mathrm{kg}$, while the change in angle was $6^{\circ}$ at slow speed and $10^{\circ}$ at fast speed. At these phases, the ankle impedance decreased since the same amount of moment generated larger displacements. These results show that the ankle reduces its impedance in the frontal plane during turning to allow the body to lean.

On the other hand, if the ankle moments increase while the ankle rotations stay the same or decrease, the ankle impedance has increased since the increase in moment did not cause a proportional increase in displacement. This was observed in the transverse plane of the right step at both speeds, where the ankle rotations during sidestep cutting at both the left and right sides were statistically the same as during straight walking, but the amount of the ankle moments increased by $0.2 \mathrm{Nm} / \mathrm{kg}$ in the external direction. The TP of the right cutting step requires more investigation to identify the contributions of the hip and ankle in the generated moments.

The results from the experiments described in this article show the importance of frontal plane movement during turning. During straight walking, body weight shifts in the frontal plane from side to side. During turning, the body leans to the inside of the turn in the frontal plane. We hypothesized that this movement allows for a more natural gait when walking on inclined planes perpendicular to the direction of motion and also accommodates ankle motions required to walk on rough surfaces. The evidence obtained from the experiments described in this article supports the assertion that a 2-DOF ankle-foot prosthesis capable of impedance modulation in each axis 
could increase the agility during gait by mimicking true ankle mechanics.

\section{CONCLUSIONS}

In this article, experiments were performed to measure ankle mechanics during straight walking and sidestep cutting at two different speeds. The study revealed no statistical difference in the sagittal plane ankle motion when comparing the sidestep cutting with straight walking. In the frontal plane, the right ankle showed progressively increasing inversion from $2^{\circ}$ to $13^{\circ}$ while the left step showed progressively decreasing inversion from $8^{\circ}$ to $-4^{\circ}$ during the slow speed test. The changes in ankle kinematics in the frontal plane from sidestep cutting to straight walking were the most significant deviation of ankle kinematics, revealing its importance for shifting the body weight and changing the walking direction during sidestep cutting. During both sidestep cutting and straight walking, the moments in the frontal plane were always in eversion. The observed eversion moments were more pronounced during the fast sidestep cutting with a normalized peak moment of $0.45 \pm 0.02 \mathrm{Nm} / \mathrm{kg}$. In the transverse plane, the least amount of moments occurred during straight walking. The transverse plane moments were significantly different when comparing straight walking with sidestep cutting; however, they were significantly smaller than the moments in the sagittal and frontal planes. The results indicate that an ankle-foot prosthesis capable of generating moments in both sagittal and frontal planes and with an impedance modulation similar to the human ankle will improve maneuverability and increase the agility for patients with limb loss. The necessity of a passive or active DOF in the transverse plane needs further investigation to estimate the contribution of the hip joint to the generated moments measured at the foot-floor interface.

\section{ACKNOWLEDGMENTS}

\author{
Author Contributions: \\ Study concept and design: E. M. Ficanha, M. Rastgaar, \\ K. R. Kaufman. \\ Acquisition, analysis, and interpretation of data: E. M. Ficanha, \\ M. Rastgaar, K. R. Kaufman. \\ Drafting of manuscript: E. M. Ficanha, M. Rastgaar, K. R. Kaufman. \\ Critical revision of manuscript for important intellectual content: \\ E. M. Ficanha, M. Rastgaar, K. R. Kaufman.
}

Statistical analysis: E. M. Ficanha, M. Rastgaar, K. R. Kaufman. Financial Disclosures: The authors have declared that no competing interests exist.

Funding/Support: This material was based on work supported by the National Science Foundation (career grant 1350154) and the Michigan Tech Research Excellence Fund (seed grant REF-RS-R01364). Institutional Review: The subjects gave written consent to participate in the experiment, which was approved by the Michigan Technological University Institutional Review Board.

Participant Follow-Up: The authors plan to inform the participants of the publication of this study.

\section{REFERENCES}

1. A roadmap for US robotics: From internet to robotics [Internet]. Computing Community Consortium; 2009 May 21. Available from:

http://www.us-robotics.us/reports/CCC\%20Report.pdf

2. Ziegler-Graham K, MacKenzie EJ, Ephraim PL, Travison TG, Brookmeyer R. Estimating the prevalence of limb loss in the United States: 2005 to 2050. Arch Phys Med Rehabil. 2008;89(3):422-29. [PMID:18295618] http://dx.doi.org/10.1016/j.apmr.2007.11.005

3. Sheppard JM, Young WB. Agility literature review: Classifications, training and testing. J Sports Sci. 2006;24(9): 919-32. [PMID:16882626] http://dx.doi.org/10.1080/02640410500457109

4. Colborne GR, Naumann S, Longmuir PE, Berbrayer D. Analysis of mechanical and metabolic factors in the gait of congenital below knee amputees. A comparison of the SACH and Seattle feet. Am J Phys Med Rehabil. 1992; 71(5):272-78. [PMID:1388973] http://dx.doi.org/10.1097/00002060-199210000-00004

5. Molen NH. Energy-speed relation of below-knee amputees walking on motor-driven treadmill. Int Z Angew Physiol. 1973;31(3):173-85. [PMID:4696826]

6. Winter DA, Sienko SE. Biomechanics of below-knee amputee gait. J Biomech. 1988;21(5):361-67. [PMID:3417688] http://dx.doi.org/10.1016/0021-9290(88)90142-X

7. Skinner HB, Effeney DJ. Gait analysis in amputees. Am J Phys Med. 1985;64(2):82-89. [PMID:3887934]

8. Bateni $\mathrm{H}$, Olney S. Kinematic and kinetic variations of below-knee amputee gait. J Prosthet Orthot. 2002;14(1):2-12. http://dx.doi.org/10.1097/00008526-200203000-00003

9. Adamczyk PG, Kuo AD, editors. Asymmetry in amputee gait: The propagating effects of weak push-off. Proceedings of the 2011 Annual Meeting of the American Society of Biomechanics; 2011; Long Beach (CA).

10. Herr HM, Grabowski AM, editors. Powered ankle-foot prosthesis improves metabolic demand of unilateral transtibial amputees during walking. Proceedings of the 2011 
Annual Meeting of the American Society of Biomechanics; 2011; Long Beach, CA.

11. Ferris AE, Aldridge JE, Sturdy JT, Wilken JM, editors. Evaluation of the biomimetic properties of a new powered ankle-foot prosthetic system. Proceedings of the 2011 Annual Meeting of the American Society of Biomechanics; 2011; Long Beach (CA).

12. Glaister BC, Bernatz GC, Klute GK, Orendurff MS. Video task analysis of turning during activities of daily living. Gait Posture. 2007;25(2):289-94. [PMID:16730441] http://dx.doi.org/10.1016/j.gaitpost.2006.04.003

13. Ventura JD, Segal AD, Klute GK, Neptune RR. Compensatory mechanisms of transtibial amputees during circular turning. Gait Posture. 2011;34(3):307-12. [PMID:21696958] http://dx.doi.org/10.1016/j.gaitpost.2011.05.014

14. Orendurff MS, Segal AD, Berge JS, Flick KC, Spanier D, Klute GK. The kinematics and kinetics of turning: Limb asymmetries associated with walking a circular path. Gait Posture. 2006;23(1):106-11. [PMID:16311202]

http://dx.doi.org/10.1016/j.gaitpost.2004.12.008

15. Hase K, Stein RB. Turning strategies during human walking. J Neurophysiol. 1999;81(6):2914-22. [PMID:10368408]

16. Segal AD, Orendurff MS, Czerniecki JM, Schoen J, Klute GK. Comparison of transtibial amputee and non-amputee biomechanics during a common turning task. Gait Posture. 2011;33(1):41-47. [PMID:20974535] http://dx.doi.org/10.1016/j.gaitpost.2010.09.021

17. Glaister BC, Orendurff MS, Schoen JA, Bernatz GC, Klute GK. Ground reaction forces and impulses during a transient turning maneuver. J Biomech. 2008;41(14):3090-93. [PMID:18804765] http://dx.doi.org/10.1016/j.jbiomech.2008.07.022

18. Hansen AH, Childress DS, Miff SC, Gard SA, Mesplay KP. The human ankle during walking: Implications for design of biomimetic ankle prostheses. J Biomech. 2004;37(10): 1467-74. [PMID:15336920] http://dx.doi.org/10.1016/j.jbiomech.2004.01.017

19. Palmer ML. Sagittal plane characterization of normal human ankle function across a range of walking gait speeds [thesis]. [Cambridge, MA]: Massachusetts Institute of Technology; 2002.

20. Gates DH. Characterizing ankle function during stair ascent, descent, and level walking for ankle prosthesis and orthosis design [thesis]. [Boston, MA]: Boston University; 2004.

21. Davis R, DeLuca P. Gait characterization via dynamic joint stiffness. Gait Posture. 1996;4(3):224-31. http://dx.doi.org/10.1016/0966-6362(95)01045-9

22. Arndt A, Wolf P, Liu A, Nester C, Stacoff A, Jones R, Lundgren $\mathrm{P}$, Lundberg A. Intrinsic foot kinematics measured in vivo during the stance phase of slow running. J Biomech. 2007;40(12):2672-78. [PMID:17368465]

http://dx.doi.org/10.1016/j.jbiomech.2006.12.009

23. Shamaei K, Sawicki GS, Dollar AM. Estimation of quasistiffness and propulsive work of the human ankle in the stance phase of walking. PLoS ONE. 2013;8(3):e59935. [PMID:23555839]

24. Rouse EJ, Hargrove LJ, Perreault EJ, Kuiken TA. Estimation of human ankle impedance during walking using the perturberator robot. Proceedings of the 4th IEEE RAS \& EMBS International Conference on Biomedical Robotics and Biomechatronics (BioRob); 2012 Jun 24-27; Rome, Italy.

25. Rouse EJ, Hargrove LJ, Perreault EJ, Peshkin MA, Kuiken TA. Development of a mechatronic platform and validation of methods for estimating ankle stiffness during the stance phase of walking. J Biomech Eng. 2013;135(8):81009. [PMID:23719922] http://dx.doi.org/10.1115/1.4024286

26. Rastgaar MA, Ho P, Lee H, Krebs HI, Hogan N. Stochastic estimation of multi-variable human ankle mechanical impedance. Proceedings of the ASME Dynamic Systems and Control Conference; 2009 Oct 12-14; Hollywood, CA.

27. Rastgaar MA, Ho P, Lee H, Krebs HI, Hogan N. Stochastic estimation of the multi-variable mechanical impedance of the human ankle with active muscles. Proceedings of the ASME Dynamic Systems and Control Conference; 2010 Sep 12-15; Boston, MA.

28. Lee H, Ho P, Krebs HI, Hogan N. The multi-variable torque-displacement relation at the ankle. Proceedings of the ASME Dynamic Systems and Control Conference; 2009 Oct 12-14; Hollywood, CA.

29. Lee H, Ho P, Rastgaar MA, Krebs HI, Hogan N. Quantitative characterization of steady-state ankle impedance with muscle activation. Proceedings of the ASME Dynamic Systems and Control Conference; 2010 Sep 12-15; Cambridge, MA.

30. Lee H, Ho P, Rastgaar MA, Krebs HI, Hogan N. Multivariable static ankle mechanical impedance with relaxed muscles. J Biomech. 2011;44(10):1901-8. [PMID:21571278] http://dx.doi.org/10.1016/j.jbiomech.2011.04.028

31. Lee H, Ho P, Rastgaar M, Krebs H, Hogan N. Multivariable static ankle mechanical impedance with active muscles. IEEE Trans Neural Syst Rehabil Eng. 2013;22(1):44-52. [PMID:24107970]

32. Ho P, Lee H, Krebs HI, Hogan N. Directional variation of active and passive ankle static impedance. Proceedings of the ASME Dynamic Systems and Control Conference; 2009 Oct 12-14; Hollywood, CA.

33. Ho P, Lee H, Rastgaar MA, Krebs HI, Hogan N. Interpretation of the directional properties of voluntarily modulated human ankle mechanical impedance. Proceedings of the 
ASME Dynamic Systems and Control Conference; 2010 Sep 12-15; Cambridge, MA.

34. Lee H, Krebs HI, Hogan N. Linear time-varying identification of ankle mechanical impedance during human walking. Proceedings of the ASME 2012 5th Annual Dynamic Systems and Control Conference Joint with the JSME 2012 11th Motion and Vibration Conference; 2012 Oct 17-19; Fort Lauderdale, FL.

35. Taylor MJ, Dabnichki P, Strike SC. A three-dimensional biomechanical comparison between turning strategies during the stance phase of walking. Hum Mov Sci. 2005;24(4): 558-73. [PMID:16129503] http://dx.doi.org/10.1016/j.humov.2005.07.005

36. Scott SH, Winter DA. Talocrural and talocalcaneal joint kinematics and kinetics during the stance phase of walking. J Biomech. 1991;24(8):743-52. [PMID:1918097] http://dx.doi.org/10.1016/0021-9290(91)90338-N

37. Wu G, Siegler S, Allard P, Kirtley C, Leardini A, Rosenbaum D, Whittle M, D’Lima DD, Cristofolini L, Witte H, Schmid O, Stokes I; Standardization and Terminology Committee of the International Society of Biomechanics; International Society of Biomechanics. ISB recommendation on definitions of joint coordinate system of various joints for the reporting of human joint motion-part I: Ankle, hip, and spine. J Biomech. 2002;35(4):543-48.

\section{[PMID:11934426]}

http://dx.doi.org/10.1016/S0021-9290(01)00222-6

38. Sasaki K, Neptune RR. Differences in muscle function during walking and running at the same speed. J Biomech. 2006; 39(11):2005-13. [PMID:16129444]

Submitted for publication February 12, 2014. Accepted in revised form November 3, 2014.

This article and any supplementary material should be cited as follows:

Ficanha EM, Rastgaar M, Kaufman KR. Ankle mechanics during sidestep cutting implicates need for 2-degrees of freedom powered ankle-foot prostheses. J Rehabil Res Dev. 2015;52(1):97-112.

http://dx.doi.org/10.1682/JRRD.2014.02.0043

ResearcherID/ORCID: Mohammad Rastgaar, PhD: A8191-2009

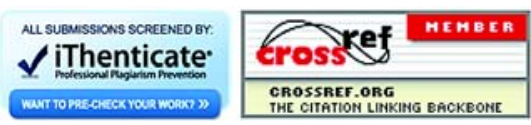

